ARTIGOS

\title{
A diferença tornada tradicional: formas de objetivação de populações indígenas ${ }^{1}$
}

\section{The difference makes traditional: forms of objectivation of indigenous populations}

\author{
Anita Guazzelli Bernardes* \\ Universidade Católica Dom Bosco, Campo Grande, Mato Grosso do Sul, Brasil
}

Camilla Fernandes Marques**

Universidade Católica Dom Bosco, Campo Grande, Mato Grosso do Sul, Brasil

Laíza Piva Mázaro***

Universidade Católica Dom Bosco, Campo Grande, Mato Grosso do Sul, Brasil

\begin{abstract}
RESUMO
Este artigo tem como temática a análise de formas de objetivação das populações indígenas mediante a construção de políticas públicas voltadas para essas populações. A reflexão apoia-se nas ferramentas conceituais foucaultianas sobre verdade e política, para examinar práticas discursivas de atenção à saúde indígena a partir de ações em saúde voltadas para essas populações. A reflexão é feita com base na análise de periódicos científicos publicados posteriormente à Política Nacional de Atenção Integral à Saúde dos Povos Indígenas. Os periódicos foram selecionados na base de dados BVS. Foram utilizados 10 artigos e legislações em saúde como fontes de informação. A escolha desses 10 artigos se deu segundo o critério de um indicador epistemológico - tradicional. O tradicional é considerado um indicador epistemológico que constitui a possibilidade de conformação de um discurso indígena. A objetivação de populações indígenas como diferença retira dessas existências a própria condição de diferença, na medida em que se estabelece o tradicional como "ser" dessa diferença.

Palavras-chave: Discurso; Formas de objetivação; Populações indígenas; Políticas públicas.
\end{abstract}

\begin{abstract}
This paper analyzes forms of objectivation of indigenous populations considering the construction of public policies for them. This reflection has been grounded on Foucauldian conceptual tools about truth and politics, in an attempt to examine discursive practices of indigenous health care in health actions directed to indigenous populations. The reflection is based on the analysis of journals published after the National Policy for Integral Attention to Indigenous Peoples Health Care. The journals were selected from BVS database. Ten articles and health regulations were used as sources of information. These ten articles were selected according to a criterion of an epistemological indicator - the traditional. The traditional has been considered as an epistemological indicator that constitutes the
\end{abstract}


possibility of conformation of an indigenous discourse. The objectivation of indigenous populations as difference takes from these existences the difference condition in itself, for it establishes the traditional as the "being" of that difference.

Keywords: Discourse; Forms of objectivation; Indigenous peoples; Public policies.

Este artigo tem como temática a análise de formas de objetivação das populações indígenas mediante a construção de políticas públicas voltadas para essas populações ${ }^{2}$. O fio condutor deste estudo constitui-se pelas discussões de Foucault (2003c) sobre verdade e política, para examinar práticas discursivas de atenção à saúde indígena a partir de ações em saúde voltadas para essas populações. A reflexão é feita com base na análise de periódicos científicos publicados posteriormente ao Decreto Lei no 3.156 de 1999, que cria o subsistema de atenção à saúde indígena dentro da Política Nacional de Atenção Integral à Saúde. Esta discussão faz parte de uma investigação voltada para o estudo do modo como as populações indígenas tornaram-se objeto de políticas públicas em saúde.

Os periódicos foram selecionados na base de dados da Biblioteca Virtual de Saúde (BVS). Como critério de seleção foi utilizado o descritor saúde indígena, no período de 2000 a 2009, em estudos sobre práticas realizadas com ou nas comunidades indígenas, além da indicação nos textos da política de saúde que organizavam essas práticas. De um total de 90 artigos, com base nesses critérios de seleção, foram escolhidos 29 textos. Como este estudo faz parte de uma pesquisa e trata-se de um recorte desta, serão utilizados dentre esses 29 textos apenas 10. A escolha desses 10 textos se deu mediante o critério de um indicador epistemológico - tradicional. $\mathrm{O}$ tradicional é considerado um indicador epistemológico que constitui a possibilidade de conformação de um discurso indígena (FOUCAULT, 2003a). O conceito de tradicional, nesta análise, correlaciona-se as idiossincrasias das populações indígenas.

O conjunto de periódicos, juntamente com legislações, compõe o que Foucault (2000a) nomeia de arquivo. O arquivo é uma ferramenta para 0 pensamento que se define pelo "sistema de seu funcionamento" ( p. 149), em que os campos de visibilidade e as regiões de dizibilidade que aí aparecem são compreendidos como acontecimentos que articulam figuras distintas e relações múltiplas, produzindo modos de objetivação, ou seja, o que é possível, no interior de suas regras, ser visto e falado.

A reflexão elege uma proposição de Foucault (2000a) que serve como ferramenta de problematização para a análise do arquivo. A proposição que torna essa discussão possível é aquela escrita por Foucault (2000a), quando o autor encerra o segundo capítulo de Arqueologia do Saber com a seguinte enunciação: "permaneceremos 
na dimensão do discurso" (p. 85). No presente artigo permanecer na dimensão do discurso é a enunciação-proposição que torna possível problematizar formas de objetivação das populações indígenas mediante a análise de um arquivo.

Não se trata, então, de investigar quais as intenções do autor, nem tampouco perscrutar uma unidade do discurso, nem origem, nem identidade, e sim condições de existência de um determinado enunciado que torna possível e legível a figura dos povos indígenas nas políticas públicas.

Os periódicos utilizados como figuras do arquivo estão dispostos no quadro abaixo e indicados por número. Como forma de diferenciação destes textos daqueles que servem como ferramentas teóricas, os periódicos são citados ao longo do artigo não pelo nome do autor, mas pelo número do texto. Além disso, aparecem entre aspas as enunciações, porém não é indicado o número da página, pois as proposições nem sempre são lineares e completas; as aspas servem como um instrumento, neste caso específico dos periódicos estudados, para separá-los do corpo da análise. 
Quadro 1: Lista de periódicos analisados

\begin{tabular}{|c|c|}
\hline Periódico & Núme ro \\
\hline $\begin{array}{l}\text { LUNARDI, R.; SANTOS, R. V.; COIMBRA JR., C. E.A. Morbidade } \\
\text { hospitalar de indigenas Xavantes, Mato Grosso, Brasil (2000-2002). } \\
\text { Revista Brasileira de E pidemiologia. São Paulo, v. 10, n. 4, p. 441- } \\
52,2007 \text {. }\end{array}$ & 01 \\
\hline $\begin{array}{l}\text { LANGDON, E. J; DIEHL, E. E. Participação e Autonomia nos Espaços } \\
\text { Interculturais de Saúde Indigena: reflexões a partir do Brasil. Saúde e } \\
\text { Sociedade. São Paulo, v. 16, n. 2, p.19-36, } 2007 .\end{array}$ & 04 \\
\hline $\begin{array}{l}\text { PAGLIARO, H.; JUNQUEIRA, C. Recuperação Populacional e } \\
\text { Fecundidade dos Kamaiurá, Povo Tupi do Al to Xingu, Brasil Central, } \\
1970-2003 \text {. Saúde e Sociedade. São Paulo, v.16, n. 2, p. 37-47, } 2007 .\end{array}$ & 05 \\
\hline $\begin{array}{l}\text { GIL, L. P. Politica de Saúde, Pluralidade Terapêtica e Identidade na } \\
\text { Amazônia. Saúde e Socied ade. São Paulo, v. 16, n. 2, p. 48-60, } 2007 .\end{array}$ & 06 \\
\hline $\begin{array}{l}\text { RIOS, L. et al. Prevalência de Parasitos Intestinais e Aspectos } \\
\text { Socioambientais em Comunidade Indigena no Distrito de Iauretê, } \\
\text { Municipio de São Gabriel da Cachoeira (AM), Brasil. Saúde e } \\
\text { Socied ade. São Paulo, v.16, n. } 2 \text {, p. } 76-86,2007 \text {. }\end{array}$ & 08 \\
\hline $\begin{array}{l}\text { PEKELMAN, R. Caminhos para uma ação educativa emancipadora: a } \\
\text { prática educativa no cotidiano dos serviços de atenção primária em } \\
\text { saúde. Rev ista de APS. Juiz de Fora, vol 1, n. } 3 \text {, p. } 295-302 \text {, jul-set, } \\
2008 \text {. }\end{array}$ & 17 \\
\hline $\begin{array}{l}\text { VARGA, I. V. D. "Racialização" das Politicas de Saúde? (nota sobre as } \\
\text { politicas de saúde para as populações negra e indigena). Saúde e } \\
\text { Sociedade. São Paulo. v. } 16, \text { n. } 2 \text {, p.178-181, 2007. }\end{array}$ & 18 \\
\hline $\begin{array}{l}\text { NUNES, H M; MONTERO, M R. de C. C. Prevalência dos } \\
\text { marcadores sorológicos dos virus das hepatites B e D na área indigena } \\
\text { Apyterewa, do grupo Parakanã, Pará, Brasil Cadernos de Saúde } \\
\text { Pública. Rio de Janeiro, v. } 3 \text {, n. } 11, \text { p. } 2756-2766 \text {, nov, } 2007 \text {. }\end{array}$ & 22 \\
\hline $\begin{array}{l}\text { FAUSTINO, R. C; CHAVES, M; TOLEDO, M J. O.; MOTA, L.T; } \\
\text { ANGELIS NETO, G.; NANNI, MR. Intervenções pedagógicas em } \\
\text { educação para a saúde realizadas junto aos grupos indigenas kaigang de } \\
\text { Ivaí e Faxinal no Paraná. Rerista Ciência, cuidad o e saúde Maringá, } \\
\text { vol } 6 \text {, supl } 2 \text {, p. } 433-441 \text {, jan-mar. } 2007 \text {. }\end{array}$ & 23 \\
\hline $\begin{array}{l}\text { KREUTZ, I.; GAIVA, MA. M; ZEREDTO, RC. S. Determinantes } \\
\text { sócio-cul turais e históricos das práticas populares de prevenção e cura } \\
\text { de doenças de um grupo cul tural. Texto \& Contexto em Enfermagem. } \\
\text { Santa Ca tarina, vol 15, n. 1, p. } 89-97 \text {, jan-mar. } 2006\end{array}$ & 27 \\
\hline
\end{tabular}

\section{1 “Permaneceremos na dimensão do discurso"}

A proposição "Permaneceremos na dimensão do discurso" (FOUCAULT, 2000a, p. 85) torna-se um enunciado quando tomada do ponto de vista dos jogos que se estabelecem em termos de relações entre campos de enunciação e regiões de visibilidade, entre o aparecimento e a delimitação que dão às enunciações seu sentido e valor de verdade. Neste caso, quando Foucault (2000b) perscruta de modo arqueológico, ou seja, permanecendo na dimensão do discurso, enunciados que na modernidade conformam a figura do louco e dos grandes internamentos, entre outros, isso acaba por servir de ferramenta conceitual para análises que se sustentam nessa forma de problematização. Mediante esse agenciamento do pensamento, pode- 
se interrogar sobre uma possível história de acontecimentos, de práticas que se pautam em um suposto que é a figura das populações indígenas. Dessa forma, não é partir de um universalismo da figura, mas das condições que a tornam um possível: saúde das populações indígenas. Permanecer na dimensão do discurso é um referencial que permite investigar os jogos de verdade, as regras de existência que, assim como forjam objetos, são as condições de operar com esses objetos.

Como foi dito, a enunciado "Permaneceremos na dimensão do discurso" (FOUCAULT, 2000a, p. 85) aparece no segundo capítulo da Arqueologia - capítulo que o autor apresenta o que considera como regularidades discursivas: formações discursivas, formação dos objetos, dos conceitos, das modalidades enunciativas, das estratégias de formação. Essas categorizações servem de instrumentos para a descrição de um discurso, que é composto por um conjunto de enunciados. Os objetos, as enunciações, os conceitos e as estratégias teóricas só são possíveis pelo discurso, ao mesmo tempo em que se apresentam como o que possibilita um discurso existir.

Um discurso sobre a saúde das populações indígenas conforma-se mediante um conjunto de regras que, entre outros acontecimentos e práticas, se encontra tanto em um plano agenciado pela reforma sanitária no Brasil, em uma política indigenista, quanto em um plano de movimentos sociais. Eleger um período a partir da formulação da Política Nacional de Atenção Integral à Saúde dos Povos Indígenas (MINISTÉRIO DA SAÚDE, 2000) Esta é não significa estabelecer que esta seja um grande acontecimento, e sim que também é efeito de condições que tornam possível falar de uma política, de um subsistema da saúde para as populações indígenas. O objetivo é interrogar-se sobre como, nas últimas duas décadas, no Brasil, começa a emergir um campo de especificidades na saúde: um plano de taxionomias não dos corpos, mas de raças, etnias, gênero, faixa etária: a Política Nacional de Atenção Integral constitui-se de um conjunto de subsistemas voltados para a mulher, o idoso, a criança, os povos indígenas. As regras de um discurso da saúde não se baseiam mais em uma anatomia geral do corpo humano, e sim em uma anatomia cultural.

Ao seguir um caminho de análise das formações discursivas e de seus objetos correlatos, Foucault (2008) tenta mostrar o modo como opera com o discurso. Ele tece as formas de compreensão do discurso numa tentativa de mostrar a distinção com a noção de estrutura, na medida em que não se trata de um Estado, mas de políticas que tornam possível uma razão de Estado. A razão de Estado conforma-se como uma economia política que precisa responder a uma urgência histórica não mais com regimes de confinamento indígena, como quando a questão era a articulação do índio com a terra e o trabalho, passando a ser uma questão indígena com taxas de morbidade e 
mortalidade de três a quatro vezes maiores que as de populações não indígenas (MINISTÉRIO DA SAÚDE, 2000). Isso encaminha para a possibilidade de pensarmos não no que o discurso queria dizer, mas no que o discurso diz. Para tanto, "permanecer na dimensão do discurso" vai conformando-se como estratégia de investigação, como aquilo que irrompe e modifica um modo de pensar.

Deleuze (2001) complementa essa discussão ao explicar sua crítica sobre a interpretação do significante e significado como ato de representação de palavras e de coisas. O interpretar, na perspectiva deleuziana, é considerar a força que dá um sentido à coisa, e não a relação entre a palavra e a coisa. O que significa operar em um plano de composições de objetos que articulam diferentes domínios e formas de utilização possíveis em razão daquilo que, exterior aos próprios objetos, os delimita, define seu limiar de existência: os estratos de saber. A reforma sanitária no Brasil possibilita a articulação de diferentes domínios de saber na saúde. É mediante a composição das ciências biológicas com as ciências humanas que se torna possível operar não apenas com uma taxionomia, exclusiva do corpo humano, mas também com uma taxionomia cultural, tendo como um princípio operativo a equidade em saúde, ou seja, os indivíduos são iguais em termos de direitos, porém diferentes em termos de demandas. Essa diversidade de demandas objetivará diferentes formas de subjetivação. Nessa linha de reflexão, não significa pensar no que a equidade quis dizer ou significar, mas no que produz no ato de dizer.

Foucault (2000a) propõe um modo de tomar o discurso quando escreve sobre as unidades deste. O autor discute a forma como devemos renunciar às análises históricas do discurso e à interpretação de um já-dito, para acolher o discurso em sua irrupção de acontecimentos e dispersão temporal - , "é preciso tratá-lo no jogo de sua instância" (p. 28). É no jogo de sua instância que encontraremos não a origem do discurso, mas a possibilidade de descrever que objetos se formam por meio de uma determinada instância discursiva, que conjunto de regras os torna possíveis, os forma como unidades, bem como o que serve como aquilo que os regula. Considerar a instância do discurso implica, nesse momento, voltar-se para os acontecimentos discursivos. A Política Nacional de Atenção Integral à Saúde dos Povos Indígenas (MINISTÉRIO DA SAÚDE, 2000) é tomada aqui não como um discurso, mas como parte de um jogo, uma instância do discurso sobre a saúde indígena, um campo de visibilidade do próprio discurso, que tem, entre outras regras, a equidade em saúde. Os periódicos científicos também produzem tanto a irrupção de acontecimentos da saúde indígena quanto o acaso de sua dispersão temporal, ou seja, não é a unidade dessas materialidades que o discurso sobre a saúde indígena produz, 
mas a possibilidade de, ao objetivar a saúde indígena, forjar aquilo que a torna possível como objeto da saúde: um campo de práticas. Para não se equivocar quanto a relacionar acontecimentos discursivos com inscrições em uma superfície linguística, em que distintos acontecimentos e distintas unidades vêm a se depositar e a se superpor, Foucault (2000a) aponta que continuar na dimensão própria do discurso significa levar em consideração as condições de existência e emergência de regularidades históricas. Para tanto, quando o autor escreve sobre a formação dos objetos, insiste em não considerá-los como inscrições; não que não o sejam, mas considera que, para a análise que pretende, isso seria insuficiente, visto que seu olhar se direciona para aquilo que torna esses objetos possíveis, para o conjunto de relações determinadas em um discurso que dão lugar e conformam certos objetos e não outros. O objetivo, então não é caracterizar objetos privilegiados, mas o modo como um discurso forma seus objetos. É refletir sobre o modo como a questão indígena conforma-se no interior de um discurso sobre a saúde da população, como a formação de um campo de visibilidade na saúde coloca a relação entre questão indígena e saúde. A formação dos objetos remete o discurso para a condição de relações e de regras estabelecidas entre diferentes "instituições, processos econômicos e sociais, formas de comportamento, sistemas de normas, técnicas, tipos de classificação, modos de caracterização" (FOUCAULT, 2000a, p. 51). Neste caso, para permanecer na dimensão do discurso, é necessário olhar para o feixe de relações que forjam um objeto, não como aquilo que o constitui internamente, mas como o que possibilita o seu aparecimento, como aquilo que, em um determinado tempoespaço, torna possível ver e falar.

\section{Da formação de objetos}

$\mathrm{Na}$ discussão sobre a formação dos objetos, Foucault (2000a) apresenta mais uma vez o que seria analisá-los permanecendo no discurso. Para tanto, ao se descrever um discurso, percebe-se que as palavras e as coisas não apresentam laços tão fortes assim como se pensa em uma análise das representações. Deste modo, nem as palavras, nem as coisas correspondem umas as outras num sentido de nomeação e espelhamento da realidade por parte da linguagem. Existe uma separação entre as palavras e as coisas, e o discurso não define a existência de uma realidade - coisas -, tampouco o uso de um vocabulário - palavras -, mas o regime de formação dos objetos, das relações que anexam palavras e coisas. Ficar no nível do próprio discurso é permanecer no "entre" as palavras e as coisas, é o nível das relações entre as palavras e as coisas por meio de práticas discursivas; não é ir no aquém ou além das palavras e das coisas, 
mas olhar a instância de aparecimento de regras que possibilitam surgir um determinado objeto.

A reforma sanitária, ao equalizar saúde e cidadania, bem como universalizar o acesso à saúde, cria a relação entre população, comunidades/povos e direitos. As comunidades indígenas passam a ser foco das ações de um direito à saúde: de "Índios do Brasil" (BRASIL, 1910), tornam-se "povos indígenas" (MINISTÉRIO DA SAÚDE, 2000), com nacionalidade brasileira, na medida em que nascem no território nacional; como habitantes do País, tornam-se sujeitos de direitos, com reconhecimento de suas especificidades de organização social (BRASIL, 1988). Desse modo, não há um objeto a ser descoberto pela relação da palavra com a coisa, mas a articulação das palavras e das coisas segundo um conjunto de regras - equidade, cidadania, população/comunidades, direito -, mediante práticas discursivas que tornam possíveis um objeto enunciado. Por isso, ficar no nível próprio do discurso é considerar que ele produz os objetos dos quais fala. Tomar o discurso enquanto uma prática que constrói objetos não é analisar o entrecruzamento das palavras e das coisas simplesmente, mas o relacionamento que caracteriza uma prática discursiva. Não é analise de léxico, ou realidade, mas descrição de regras de formação de objetos.

Interrogar sobre as formas de objetivação das populações indígenas é considerá-la como um evento criado por ocasião de uma rede de associações, e cada substituição nessa rede de associações modifica e cria outro evento, em que "não há uma associação direta entre uma assertiva direta e um estado de coisas, mas uma assinatura única elaborada por associações e substituições através do espaço conceitual" (LATOUR, 2001, p. 188). Esse processo começa com atributos (questão indígena, terra, instituições, teorias indigenistas) que colocam as populações indígenas em discurso e terminam por substanciá-las, ou seja, torná-las delimitadas, territorializadas como organizações próprias, com seus costumes, línguas, crenças e tradições. O conceito de "são reconhecidos aos índios" (BRASIL, 1988, p. 151) traz um novo atributo à série, não mais o quem é indígena, mas o reconhecimento de ser indígena. Ser indígena, no Título VIII da Constituição Federal de 1988 (BRASIL, 1988), cria outra ontologia e a necessidade de novas articulações no campo do direito e da "ordem social". Reconhecer aos índios suas organizações sociais e os direitos originários sobre as terras que tradicionalmente ocupam coloca-os no campo da proliferação de marcas diferentes: a proveniência de distintas línguas, costumes, tradições, que vão criar necessidades de outra articulação do direito, não mais ao índio, mas aos índios como multiplicidade. E é a essa multiplicidade que a "ordem social" precisará responder: 
Quando um fenômeno existe "em definitivo", isso não quer dizer que existirá eternamente independentemente de toda prática e disciplina, mas que foi inserido numa instituição de massa muito dispendiosa, que tem de ser monitorada e protegida com o máximo cuidado (LATOUR, 2001, p. 181).

Para sustentar essa discussão, recorremos à Foucault (2000a, p. 70), que, ao escrever sobre a formação de conceitos, explica que as regras próprias das práticas discursivas não estão em um sujeito cognocente, nem tampouco em um sujeito psicológico, mas no próprio discurso, pois "se impõem, por conseguinte, segundo um tipo de anonimato uniforme, a todos os indivíduos que tentam falar nesse campo enunciativo". As regras não são resultado de uma sedimentação histórica, mas um conjunto de jogos anônimos que possibilitam a formação de objetos e de conceitos, por isso, fica-se no fala-se e não no falou. O fala-se marca o ponto de entrecruzamento do corpo com a história, de um "corpo inteiramente marcado pela história, e a história arruinando o corpo" (FOUCAULT, 2000b, p. 267), um corpo que se torna "índios" pelas organizações sociais, línguas, costumes, tradições particulares, como objetos da "ordem social". Essas marcas particulares não estabelecem a origem do "ser índio", um "eu índio", uma síntese do ser, uma identidade; antes, apontam a conformação de atributos produzidos por acontecimentos heterogêneos que tornam a figura "índios" um objeto-conceito. Esses acontecimentos heterogêneos surgem da articulação de distintas disciplinas - antropologia/etnografia, medicina, direito, educação com a conformação de um Estado, de políticas públicas que tanto o justificam quanto o tornam possível.

É por meio da descrição do discurso que se delineia o sistema de regras que são colocadas em prática para que surjam certos objetos, conceitos, teorias e sujeitos. Na descrição de enunciados de um discurso, define-se que o discurso, mediante os enunciados ${ }^{3}$, não é aquilo que nomeia e atribui sentidos aos objetos, e sim:

Em vez de dar um sentido a essas unidades, coloca-as em relação com um campo de objetos; em vez de lhes conferir um sujeito, abre-lhes um conjunto de posições subjetivas possíveis; em vez de Ihes fixar limites, coloca-as em um domínio de coordenação e de coexistência; em vez de lhes determinar a identidade, aloja-as em um espaço em que são consideradas, utilizadas e repetidas (FOUCAULT, 2000a, p. 122).

Ficar no nível do discurso é referir-se às coisas ditas, é ficar na dimensão de sua existência enquanto dito de um espaço-tempo determinado - dito que diz respeito a duas camadas, duas estratificações: visibilidade e legibilidade, ver e falar, forma dos Povos Indígenas (MINISTÉRIO DA SAÚDE, 2000). 
Portanto, tomar como coordenada o "permanecer no nível próprio do discurso" não é fazer uma análise do discurso, e sim uma descrição dos jogos, das regras, das estratégias que de dão expressão e substância de expressão. Enquanto que a forma de expressão, no que tange à objetivação das populações indígenas, no campo das políticas públicas de saúde, é o direito e sua correlação com a saúde, a sua substância de expressão é a figura existencial de índios. A forma de expressão é um agenciamento coletivo de enunciação ${ }^{4}$ : saúde das populações indígenas como uma questão social; a substância de expressão é um agenciamento maquínico de $\operatorname{corpos}^{5}$ : a visibilidade da noção de índios articulada a distintas línguas, costumes e tradições (DELEUZE, 1988). O jogo de regras, o conjunto de coordenadas e coexistência - direito, saúde, populações indígenas -, trata-se daquilo que torna possível um dito aparecer, existir, permanecer, manifestar-se, e nenhum outro em seu lugar.

A articulação entre direito, saúde e populações indígenas não se encontra em uma dimensão latente do discurso, em uma descrição do discurso, mas "aquilo a que nos dirigimos está na evidência da linguagem efetiva" (FOUCAULT, 2000b, p. 126). O conjunto de coordenadas que agencia essa relação entre direito, saúde e populações indígenas o faz mediante formas de expressão, como ordem social e reconhecimento de organização social heterogênea. 0 dito não é compreendido por aquilo que poderia ser dito, mas não o foi, tampouco é algo que faz referência ou remete a outro algo. Também não se refere a uma opinião comum, a uma representação social. Por dito entende-se o conjunto de coisas ditas efetivamente em um determinado tempo-espaço - Constituição, textos referentes às políticas públicas de saúde, periódicos científicos -, um conjunto de relações, regularidades, transformações, um domínio que cria uma região de visibilidade e enunciação de objetos e sujeitos: Política Nacional de Atenção Integral à Saúde conformam um determinado discurso, neste caso, políticas públicas de saúde para as populações indígenas. Não diz respeito a interrogar a linguagem na direção do que ela remete, mas a descrever aquilo que torna a linguagem possível, aquilo que a produz e ao mesmo tempo aquilo que engendra em termos de formação de objetos e sujeitos: povos indígenas, dos índios, populações indígenas. Implica olhar uma região de opacidade, mas não o que estaria escondido. O olhar volta-se para a periferia, para a superfície, para a modalidade de seu aparecimento. Regras de aparecimento enquanto modo de ser de uma linguagem, mas também condições de apropriação e utilização. Essas condições de aparecimento, apropriação e utilização do discurso são aquilo que Foucault (2000a) nomeia de positividades, ou seja, aquilo que ao mesmo tempo produz o discurso e os objetos e sujeitos desse discurso.

Operar com a dimensão do próprio discurso não é considerá-lo como 
um documento, mas como um monumento ${ }^{6}$ (DELEUZE, 1988). Incorporar elementos próprios e pertencentes aos sistemas de atenção à saúde encarnados nas culturas e práticas locais indígenas (texto 4), como aponta um dos periódicos, não é considerado uma representação do pensamento de uma época, mas aquilo que torna possível pensar em uma época; portanto, não é um documento que determina este dito, mas justamente as condições que tornam este dito parte de uma proveniência que conforma um monumento: populações indígenas e saúde. A cultura e práticas locais articulam-se no campo que territorializa, que substancializa a existência de populações indígenas conjuntamente com o reconhecimento de suas organizações sociais particulares. Isso significa dizer que a investigação, ao voltar-se para o nível das coisas ditas nos próprios periódicos e legislações, deve abordar outros conceitos correlatos da noção de dito. Pensar nas coisas ditas é voltar-se para as positividades, para a produção de uma figura/monumento com a cultura e as práticas locais, para aquilo que a tornou possível, para aquilo que se faz carne na instância de seu aparecimento: o direito desses povos à sua cultura (MINISTÉRIO DA SAÚDE, 2000). As ferramentas arqueológicas que tomam um discurso como monumento referem-se à proveniência dos acontecimentos, da formação dos objetos, conceitos e sujeitos, das estratégias teóricas forjadas pelo fala-se. O fala-se é a dimensão própria do discurso, é prática discursiva que se encontra entre as palavras e as coisas.

Ficar no fala-se, ou no volume próprio do discurso (FOUCAULT, 2000a), outra enunciação que reforça o "permaneceremos na dimensão própria do discurso", abre um espaço de multiplicação, um emaranhado de interpositividades que tira a permanência através dos tempos dos objetos e os coloca como instâncias provisórias e singulares. O volume próprio do discurso, a dimensão própria do discurso é o olhar que o torna um monumento, e não outro discurso. Cultura e práticas locais articulam-se em princípios de atenção diferenciada que também se amplia para diferenças epidemiológicas. A figura indígena deixa de ser o exótico para tornar-se o diferente, um diferente assegurado por um conjunto de práticas normativas. Um monumento que deve ser descrito em sua conformação, em suas reentrâncias, em sua localização, no modo como é utilizado, no feixe de relações que o torna possível - é do diferente que proliferam os enunciados, as reentrâncias. Diferente não como origem, não como essência de um discurso, mas como aquilo que, ao jogo do acaso de um conjunto de disciplinas, torna possível o seu aparecimento. $O$ diferente vai articular-se ao tradicional: "alguns hábitos sanitários tradicionais, saber tradicional, manutenção desse padrão de família" (texto 1,5 e 8 ).

O direito do diferente acaba por correlacionar o diferente com o tradicional; o tradicional, com "agências subjetivas" (texto 6). O 
diferente não está nas marcas do corpo, mas nas marcas dos hábitos, das tradições, da língua, do costume:

\footnotetext{
Se, para a biomedicina, a eficácia das plantas radica nos efeitos que seus componentes bioquímicos têm no corpo, as teorias indígenas - e aqui encontramos variações de uma cultura para outra - atribuem sua eficácia a agências subjetivas (texto 6).
}

O diferente, o tradicional, o subjetivo, cria um espaço entre um nós e um eles, bem como uma estratégia que deve articular "diálogo entre o saber tradicional e o saber científico" (texto 8). Não se trata de uma interpretação do monumento, pois se cairia novamente em uma busca pela origem e pela autoria: quem fez o monumento e por quê. Fica-se na própria descrição, no dito que não poderia ser outro, "é a descrição sistemática de um discurso objeto" (FOUCAULT, 2000a, p. 160), de um discurso que produz um "diferente". A arqueologia trata o discurso como monumento, mas não como a grande obra, aquilo que marca uma época, e sim como monumentos do cotidiano, como práticas micropolíticas. A descrição do discurso em sua dimensão própria e enquanto prática não se refere a mostrar como a prática determinou o sentido e a forma do discurso, mas a como e por que uma determinada prática faz parte das condições de emergência, inserção e funcionamento de certo discurso. Às tecnologias semióticas, articulam-se as tecnologias de poder.

\section{Discurso e luta política}

Apontar que um discurso tem suas regras próprias de aparecimento, com condições de apropriação e utilização, lança a reflexão para aquilo que é dimensão constituinte das relações de forma. O discurso é uma forma, uma tecnologia semiótica, pois forja um campo de dizibilidade e uma região de visibilidade, entretanto, tem como conjunto propulsor relações de força. As relações de força não falam e não veem, mas fazem falar e ver: "preenchimento de ficha individual de inquérito" (texto 22), utilizada nos acompanhamentos de atenção à saúde das populações indígenas por agentes de saúde indígena. Essas fichas individuais de inquérito são uma tecnologia de normatização e esquadrinhamento das populações indígenas. Constituem-se de dados que circunscrevem idade, sexo, etnia, data de abertura da ficha, relações parentais, nomes utilizados nas diferentes fases da vida, local de moradia. São utilizadas pelos agentes de saúde indígena e tornam-se um instrumento de controle das ações dos próprios agentes e das populações que eles acompanham. Neste caso, não se trata apenas do que é descrito, ou seja, das categorias que objetivam essas populações, mas do 
protocolo que deve ser seguido para acompanhá-las. As fichas de inquérito, entre outras tecnologias de governo, forjam uma entrada de forças, uma irrupção que permite às populações indígenas tornarem-se um campo possível de ações de saúde; trata-se de um procedimento que fixa obrigações e direitos - é necessário o preenchimento da ficha para ter acesso ao direito à saúde -, marcando nos corpos o que são, quem são, de onde são.

O discurso é constituído por relações de força, pois se trata de uma estratégia de luta, de uma luta política, de enfrentamentos entre o tradicional e o científico. A primeira procura por cuidados em saúde é feita por referências nas próprias comunidades:

Problemas de saúde são causa frequente de visitas à cidade ou a outras aldeias, mas normalmente não se procura ajuda no hospital ou em postos de saúde, senão que se recorre a curandeiros e xamãs mestiços ou indígenas, cujos sistemas nosológicos e terapêuticos têm similitudes significativas (texto 6).

Entretanto, a ênfase nas estratégias de saúde médico-sanitárias reforça uma racionalidade que refere as tecnologias indígenas como de baixa complexidade: "os agentes de saúde indígenas tratam os problemas de saúde leves" (texto 6), enquanto que a:

\footnotetext{
Melhoria das condições de saúde e a queda da mortalidade, decorrente das ações médico-sanitárias levadas a efeito nesse período, teriam garantido, também, o aumento da sobrevivência de recém-nascidos e de crianças na primeira infância (texto 5).
}

A integração e o diálogo entre saber tradicional e científico marcam uma distinção e objetivam o tradicional como menos complexo e resolutivo do que o científico.

As relações de força existem nos interstícios entre o ver e o falar, na disjunção entre o ver e o falar, o poder de afetar e de ser afetado: estratégias tradicionais e científicas. É no espaço das forças que se encontram os potenciais de mudança; é pelas estratégias políticas que um discurso está sempre em vias de se desfazer:

O contato com a biomedicina é relativamente limitado e provém, principalmente, de fontes não especializadas, isto é, existe um uso frequente de remédios farmacêuticos, mas trata-se de um uso leigo, sem consulta a um especialista ou a uma pessoa com uma mínima formação (texto 6).

A biomedicina aproxima as tecnologias científicas, porém, as populações indígenas apropriam-se destas mediante um "uso leigo". Faz-se utilizar, mas utiliza-se de um modo que escapa à prescrição científica. 
De acordo com Foucault (2003b, p. 229):

\begin{abstract}
Produzem-se verdades. Essas produções de verdade não podem ser dissociadas do poder e dos mecanismos de poder, ao mesmo tempo porque esses mecanismos de poder tornam possíveis, induzem essas produções de verdades e porque essas produções de verdade têm, elas próprias, efeitos de poder que nos unem, nos atam.
\end{abstract}

A Constituição Federal de 1988 (BRASIL, 1988) disporá sobre as populações indígenas, conjuntamente com a Lei 8080 (BRASIL, 1990), uma política específica para atenção à saúde indígena por meio da Política Nacional de Atenção Integral à Saúde dos Povos Indígenas. Essa política irá conformar um campo de práticas de governo dessas populações. Foucault (2008), ao referir relações de poder, não se centraliza na figura do Estado, tampouco em uma Lei, mas em domínios que se tornam possíveis justamente por uma razão de Estado, entendida como a racionalização de um conjunto de práticas heterogêneas tornadas necessárias para construir e edificar a figura de um Estado:

A Funasa assumiu completamente a atenção à saúde indígena, realizada por meio dos polos-base localizados em cada um dos municípios e ligados aos $\mathrm{DSEls}^{7}$ regionais. Os polos-base são atendidos pelas Equipes Multidisciplinares de Saúde Indígena (texto 6).

Essas práticas constituem-se em distintos campos de saber, como o das ciências humanas e biológicas, que acabam por tornar-se "ofertas de serviço ao Estado, propondo-se a sua efetuação, pretendendo fornecer as melhores máquinas em função das tarefas ou dos objetivos do Estado" (DELEUZE, 1998, p. 151).

O discurso, como um conjunto de verdades, é o que permite a todo momento que um enunciado seja considerado verdadeiro, sendo que este atar-se a um enunciado como verdadeiro só é possível mediante a relação de um conjunto de forças:

Com a criação e a operacionalização do subsistema de saúde indígena, a participação indígena em organismos colegiados, como Conselhos Municipais, Estaduais e Nacional de Saúde, Conselhos Distritais de Saúde Indígena (Condisi) e Conselhos Locais de Saúde Indígena, é assegurada por direito (texto 4).

Conjunto de forças não como instância superior, mas como dimensão do próprio nível do discurso. Operar, então, no próprio nível do discurso é percorrer uma superfície de composição entre relações de forma e força, é interrogar o que permite e justifica que um objeto se torne uma evidência, uma verdade, legível, real: "práticas de cuidado à saúde tidas como 'tradicionais' ou alternativas, que são 
concomitantes ao biomédico" (texto 4). O tradicional é reconhecido quando articulado ao biomédico.

Dessa forma, verdade é efeito de relações de poder, ao passo que relações de poder se justificam e se atualizam em verdades: "a proporção de partos (indígenas) hospitalares é preconizada como uma medida da acessibilidade e da qualidade da atenção básica à saúde" (texto 6). A qualidade encontra-se no uso de um estabelecimento de saúde não-tradicional. A qualidade é registrada pela ida das populações indígenas ao sistema de saúde, e não do sistema de saúde às populações indígenas. A atenção à saúde indígena por equipes de saúde não-indígenas é feita para realizar a vacinação, o atendimento básico, e fornecer orientações referentes a diversos aspectos da saúde (higiene, prevenção de DST/AIDS, etc.), uso de anticoncepcionais, dentro das comunidades (texto 6). O jogo de forma e força reside justamente nesse confronto entre 0 tradicional e o científico. À objetivação do uso de estabelecimentos de saúde não- "tradicionais" como referência de qualidade dos serviços, responde-se com "apenas em ocasiões em que o paciente está à beira da morte, ele é levado a um posto de saúde existente numa comunidade mestiça a dia e meio de viagem. Problemas de saúde são causa frequente de visitas à cidade ou a outras aldeias, mas normalmente não se procura ajuda no hospital ou em postos de saúde" (texto 6).

Deleuze (1998) auxilia nesta compreensão quando considera que indivíduos, grupos, objetos são constituídos por conjuntos de linhas diversas. As linhas são composições que criam o que foi apontado anteriormente por regiões de visibilidade e campos de dizibilidade. É mediante o entrecruzamento de linhas que se produzem modos de objetivação, ou seja, é no encontro de linhas que um objeto se torna um possível. É no encontro de diversas linhas que certas existências ordinárias e sem glória, que passariam à margem da história (FOUCAULT, 2003b), se tornam, por exemplo, uma questão de políticas públicas. Um subsistema de atenção à saúde torna-se um possível em razão da emergência e articulação de linhas:

\footnotetext{
Entre as recomendações relevantes para pensar a atenção diferenciada, citamos duas: 1) garantir a participação política das nações indígenas na formulação, no planejamento, na gestão, na execução e na avaliação das ações e dos serviços de saúde; 2) assegurar o respeito e o reconhecimento das formas diferenciadas das nações indígenas no cuidado com a saúde (texto 4 ).
}

A participação e o reconhecimento das formas diferenciadas não são figuras de linguagem, mas linhas que contornam um território indígena na saúde, uma ontologia que opera com um discurso sobre as populações indígenas tornado admissível a partir de um indicador 
epistemológico - o tradicional -, que engendra não apenas a pluralidade de um "ser indígena" com base nas diferentes "nações indígenas", mas também o estabelecimento da categoria jurídica que assegura essa diversidade: "o direito desses povos à sua cultura" (texto 4).

Esse conjunto de linhas diversas conforma o que Deleuze (1998) entende por território. Os processos de territorialização são considerados formas de produção de uma existência, de contornos existenciais. Os contornos são possíveis em razão da composição de linhas nomeadas de segmentárias ${ }^{8}$. As linhas segmentárias, neste plano de compreensão, aproximam-se do que Foucault (2003c) discute sobre a relação entre poder e verdade, pois dependem de máquinas binárias, de dispositivos de poder e de planos de organização.

As linhas segmentárias dependem de máquinas binárias quando consideradas como dicotômicas: índios e não-índios, tradicional e ciência, por exemplo. Essa relação estabelece campos de dizibilidade e regiões de visibilidade determinados espacial e temporalmente: "a partir da reforma sanitária, a Conferência (I Conferência Nacional de Proteção à Saúde do Índio, realizada em 1986) objetivava avaliar a situação de saúde dos índios e criar uma política efetiva para os povos indígenas" (texto 4). As linhas produzem vínculos entre elementos distintos e os colocam em correlação - etnias indígenas e direito - , e em sucessão, como quando se conforma a figura indígena a partir da não-indígena. A figura "Povos Indígenas" que se formula na "Política Nacional de Atenção Integral à Saúde dos Povos Indígenas" (MINISTÉRIO DA SAÚDE, 2000) coloca o indígena não mais como o índio, como uma unidade/identidade como aparecia na política anterior - "Modelo de Atenção Integral à Saúde do Índio" (MINISTÉRIO DA SAÚDE, 2000) e "Conferência Nacional de Proteção à Saúde do Índio" (MINISTÉRIO DA SAÚDE, 2000) -, mas como diversidade, pois "reconhecem aos povos indígenas suas especificidades étnicas, culturais e seus direitos territoriais" MINISTÉRIO DA SAÚDE, 2000, p. 3). Do índio e do não-índio como classificações raciais, as máquinas binárias forjam os povos indígenas como categorias étnicas, em que os elementos binários não se encontram mais na oposição entre o ser e não ser indígena apenas, mas entre o tipo de indígena que se é, qual o espaço geográfico que ocupa, qual a proximidade com o não-indígena e as formas de diálogo entre o tradicional e o científico.

A migração que ocorre nas últimas décadas em termos de gestão da saúde indígena entre Fundação Nacional de Saúde (FUNASA), Fundação Nacional do Índio (FUNAI), Serviço de Proteção ao Índio e Trabalhadores Nacionais (SPI) conforma aquilo que, de acordo com Deleuze (1998), constitui as linhas em termos de código-território, em dispositivos de poder, ou seja, em cada segmento ao qual 
correspondem essas migrações, fixam-se códigos e territórios: tratase de um exercício de domínio de práticas de governo que, segundo regras e objetivos de conjunto, anexam a saúde indígena à terra, a um subsistema da saúde, à justiça, à integração nacional, ao trabalho. A Constituição Federal de 1988 (BRASIL, 1988) dispõe sobre os povos indígenas no Título VIII Da Ordem Social, no Capítulo VIII, intitulado "Dos Índios", sobre o reconhecimento de "sua organização social, costumes, línguas, crenças e tradições, e os direitos originários sobre suas terras que tradicionalmente ocupam, competindo à União demarcá-las, proteger e fazer respeitar todos os seus bens" (BRASIL, 1988, p. 155). A "ordem social", que tem como objetivo o "bem-estar e a justiça sociais", cria um capítulo específico aos "índios", mas indicando a pluralidade que compõe essa categoria social, separado do capítulo anterior, que dispõe sobre a família, a criança, o adolescente e o idoso. Circunscreve, assim, uma questão indígena ligada à terra e ao reconhecimento de suas especificidades, um código território de ações de bem-estar, justiça social e integração nacional - uma racionalização de práticas de governo, de uma razão de Estado, que inclui o índio na categoria outro que não família, criança, adolescente e idoso. Os códigos permitem a regulação do conjunto, fazem ver e falar em uma determinada língua, em uma determinada sociedade: sociedades indígenas e nãoindígenas. O território marca geograficamente a conformação de espaços, quem e o que habita cada um desses espaços.

Os planos de organização justamente tornam possível a "ordem social", a produção de bem-estar e justiça social - "envolvem um certo plano que concerne, a um só tempo, às formas e seu desenvolvimento, aos sujeitos e sua formação" (DELEUZE, 1998, p. 151), colocam em ordem as formas e os sujeitos: "Dos índios". Ao criarem uma territorialização indígena, os planos de organização estabelecem as separações, o esquadrinhamento da população em subconjuntos: índios, família, criança, adolescente, idoso. A cada subconjunto, corresponderá uma política pública específica, um plano, como no caso da saúde indígena, que o organiza como um território ontológico que pressupõe ações voltadas para "concepções, valores e práticas relativos ao processo saúde-doença próprios a cada sociedade indígena e a seus diversos especialistas" (texto 4). Os planos de organização, ao operarem em uma dimensão suplementar, acabam por inspirar segmentações; são ações pedagógicas que "repõem em ordem as formas e os sujeitos em seu lugar" (DELEUZE, 1998, p. 151): "práticas populares adotadas nos cuidados" (texto 17); "intervenções pedagógicas em educação para a saúde indígena" (texto 23); "práticas educativas no cotidiano da atenção primária à saúde indígena" (texto 27 ). 


\section{A diferença tornada o tradicional}

As formas de objetivação das populações indígenas, neste estudo, ao partirem do indicador epistemológico "tradicional", estabelecem um campo de produção de diferença. Esse campo, no entanto, não é marcado pelo que Deleuze (2006) aponta como diferença da diferença, e sim pela diferença que é tornada parte do igual, do mesmo. A diferença da diferença diz respeito a considerar que um elemento não é submissível ao outro, como acontece quando se opera com uma lógica identitária. Na lógica identitária a diferença é uma oposição binária, essencializada e produto da identidade, do mesmo. No que diz respeito à diferença da diferença, a lógica é da alteridade, ou seja, o mínimo é a diferença, não a origem, tampouco o início, mas aquilo que provoca processos de territorialização. A produção de diferença, aqui, reside justamente em uma estratégia do discurso indígena que, ao objetivar um território ontológico da diversidade indígena, acaba por iluminar essas existências sob uma racionalidade do direito que se dá, que reconhece, que tira de uma região de opacidade.

O reconhecimento da diversidade e da diferença, como enunciado do discurso indígena, é uma resposta a uma urgência histórica, é uma emergência de estratégia de lutas por imposições de sentidos. $O$ tradicional torna-se uma ferramenta mediante a qual é possível um processo de borrar fronteiras, de tornar o outro igual, não em termos de igualdade de direitos, de acesso a suportes sociais, mas um igual, na medida em que potenciais de diferença são conformados em um mesmo, marcado pelo "é diferente" - um diferente não mais como diferença, pois já se tornou um campo de visibilidade e dizibilidade, já apresenta marcas identitárias que o posicionam não apenas em termos de rede discursiva, mas de estratégias específicas de governo. A objetivação de populações indígenas como diferença retira dessas existências a própria condição de diferença, pois agora é visível e enunciável a diferença e se estabelece o "ser" dessa diferença: o tradicional.

\section{Referências}

BRASIL. Decreto $n^{\circ}$ 8.072, de 20 de junho de 1910. Cria o Serviço de Proteção aos índios e Localização de trabalhadores Nacionais e Aprova o Respectivo Regulamento. Acervo microfilmado do Setor de Documentação (SEDOC), do Museu do Índio/ Fundação Nacional do Índio - Ministério da Justiça, 2008.

BRASIL. Constituição da República Federativa do Brasil de 1988. São Paulo: AASP, 2008. 
BRASIL. Lei no 8080 de 1990. Dispõe sobre as condições para a promoção, proteção e recuperação da saúde, a organização e o funcionamento dos serviços correspondentes e dá outras providência. Disponível em: <http://portal.saude.gov.br/portal/arquivos/pdf/lei8080.pdf>. Acesso em: 12 mar. de 2008.

DELEUZE, G. Foucault. São Paulo: Brasiliense, 1988. . Diálogos. São Paulo: Editora Escuta, 1998.

$\overline{2} \overline{0} \overline{0} \overline{1}$ Nietzsche e a Filosofia. Porto, Portugal: Editora Rés, Diferença e Repetição. Rio de J aneiro: Graal, 2006.

DELEUZE, G.; GUATTARI, F. Mil platôs, capitalismo e esquizofrenia. Rio de J aneiro: Ed. 34, 1997.

FOUCAULT, M. A arqueologia do saber. Rio de Janeiro: Forense Universitária, 2000a.

. Prefácio à edição inglesa. In: Ditos \& escritos II . Rio de Janeiro: Forense Universitária, 2000a, p. 182-187. - Nietzsche, a Genealogia, a História. In: Ditos \& escritos II. Rio de Janeiro: Forense Universitária, 2000b, p. 260281.

Da natureza humana: justiça contra poder. In:

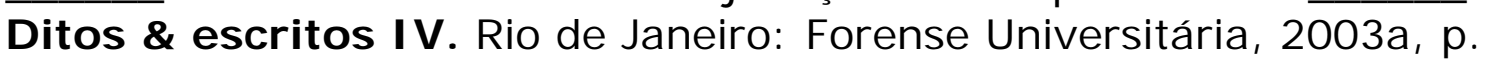
87-132.

A vida dos homens infames. In: Ditos \& escritos IV. Rio de Janeiro: Forense Universitária, 2003b, p. 203-222.

Poder e saber. In: Ditos \& escritos IV. Rio de Janeiro: Forense Universitária, $\overline{2} \overline{0} \overline{0} \overline{3} \bar{c}$, p. $223-240$.

$\overline{2} \overline{0} \overline{0}$.

Nascimento da biopolítica. São Paulo: Martins Fontes,

LATOUR, B. A esperança de Pandora. Bauru, SP: EDUSC, 2001. MINISTÉRIO DA SAÚDE. Política Nacional de Atenção à Saúde dos Povos Indígenas, 2000. Disponível em: <http://portal.saude.gov.br/portal/arquivos/pdf>. Acesso em: 12 mar. 2008.

\section{Endereços para correspondência}

\section{Anita Guazzelli Bernardes}

Universidade Católica Dom Bosco, Mestrado em Psicologia, Av. Tamandaré, 6000, Jardim Seminário, CEP 79117-900, Campo Grande-MS, Brasil.

Endereço eletrônico: anitabernardes@ig.com.br

Camilla Fernandes Marques

Universidade Católica Dom Bosco, Mestrado em Psicologia, Av. Tamandaré, 6000, Jardim Seminário, CEP 79117-900, Campo Grande-MS, Brasil.

Endereço eletrônico: camilla.fmt@hotmail.com

Laíza Piva Mázaro

Universidade Católica Dom Bosco, Mestrado em Psicologia, Av. Tamandaré, 6000, Jardim Seminário, CEP 79117-900, Campo Grande-MS, Brasil. 
Endereço eletrônico: laizapiva@hotmail.com

Recebido em: 16/06/2010

Reformulado em: 16/09/2010

Aceito para publicação em: 18/09/2010

Acompanhamento do processo editorial: Deise Mancebo

\section{Notas}

*Psicóloga; Doutorado em Psicologia pela Pontifícia Universidade Católica do Rio Grande; Docente e pesquisadora do Programa de Pós-graduação em Psicologia da Universidade Católica Dom Bosco.

**Graduanda em Psicologia; Bolsista de Iniciação Científica pela Universidade Católica Dom Bosco.

***Graduanda em Psicologia; Bolsista do CNPq de Iniciação Científica da Universidade Católica Dom Bosco.

${ }^{1}$ Este texto faz parte de uma pesquisa financiada pelo CNPq e pela Universidade Católica Dom Bosco.

${ }^{2}$ Esta pesquisa faz parte de um projeto iniciado em 2008, que tem como objetivo geral as formas de objetivação das populações indígenas pelas políticas públicas de saúde. As análises começaram nas políticas do Serviço de Proteção ao Índio e Trabalhadores Nacionais (SPI) a partir de 1910 até 1967, data de criação da Fundação Nacional do Índio e relatórios de dois postos de aldeamento do SPI situados em MS neste período. Posteriormente se partiu para a análise da Constituição Brasileira de 1988, documento de regulamentação do Sistema Único de Saúde, para então selecionar periódicos científicos produzidos a partir da criação do subsistema de saúde, organizado com base na Política Nacional de Atenção Integral aos Povos Indígenas.

${ }^{3} \mathrm{O}$ discurso é constituído por um conjunto de enunciados que podem tanto reforçarse quanto antagonizar-se.

${ }^{4}$ Por agenciamento coletivo de enunciação entende-se um conjunto de elementos semióticos e pragmáticos heterogêneos de distintas materialidades sempre produzidos que pertencem a um estrato de saber. Agenciamento é uma forma conceitual de diferenciar das noção de estrutura (DELEUZE; GUATARRI, 1997).

${ }^{5}$ Agenciamento maquínico de corpos diz respeito as formas de produção técnica de materialidades corporais, trata-se de traços de intensidade, de relações de força que se relacionam entre si como uma máquina, são agenciamentos pragmáticos (DELEUZE; GUATARRI, 1997).

${ }^{6}$ Deleuze (1988, p. 63) na discussão que faz do texto de Foucault "Arqueologia do Saber", considera monumento como um teatro de enunciados, em que nada há de oculto e que o olhar deve voltar-se para "descrever a própria cortina ou o pedestal, pois nada há atrás ou embaixo".

${ }^{7}$ Distrito Sanitário Especial Indígena.

${ }^{8}$ Deleuze (1998) descreve também outras linhas: moleculares e de fuga. 